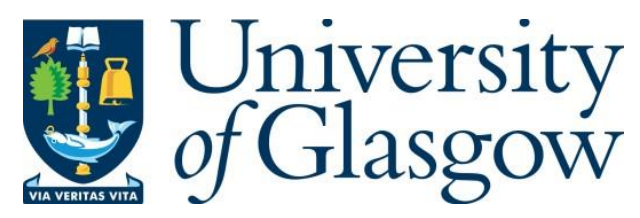

Ang, G. C., Lim, W. S. and Yeo, W. M. (2016) Market structure and the value of overselling under stochastic demands. European Journal of Operational Research, 252(3), pp. 900-909.

There may be differences between this version and the published version. You are advised to consult the publisher's version if you wish to cite from it.

http://eprints.gla.ac.uk/155609/

Deposited on: 19 January 2018

Enlighten - Research publications by members of the University of Glasgow http://eprints.gla.ac.uk 


\title{
Market Structure and the Value of Overselling Under Stochastic Demands
}

\author{
Geoffrey A. Chua ${ }^{1}$, Wei Shi Lim ${ }^{2}$, Wee Meng Yeo*3
}

April 22, 2016

\begin{abstract}
In the operations management literature, traditional revenue management focused on pricing and capacity allocation strategies in a two-period model with stochastic demand. Inspired by travel and lodging industries, we examine a two-period model in which each seller may also adopt the overselling strategy to customers whose valuations are differentiated by timing of arrivals. Widely seen as a popular hedge against consumers' skipping reservations, we extend the stylized approaches of Biyalogorsky et al (1999) and Lim (2009) to understand the value of overselling under various market structures. We find that contrary to existing literature, the impact of period-two pricing competition from overselling spills over to period-one such that overselling may not always be a (weakly) dominant strategy once unlimited early demand ceases to hold in a duopoly regime. We provide some numerical studies on the existence of multiple equilibria at the capacity allocation level which actually lead to different selling strategies at the equilibrium despite identical market conditions and firm characteristics.
\end{abstract}

\section{Keywords: pricing, overbooking, overselling, revenue management, competition}

\footnotetext{
${ }^{1}$ Corresponding author, Nanyang Business School, Nanyang Technological University, Phone: +65 6790 6140, Fax: +65 6792 2313, Email: gbachua@ntu.edu.sg,

${ }^{2}$ NUS Business School, 15 Kent Ridge Drive, National University of Singapore, Singapore 117592. Email: weishi@nus.edu.sg.

${ }^{3}$ Singapore Institute of Manufacturing Technology, A*STAR. Email: wmyeo@SIMTech.a-star.edu.sg. *The authors have made equal contribution to this paper and are therefore arranged in alphabetical order.
} 


\section{Introduction}

The practice of overbooking is commonly observed in travel and lodging industries where sales volume typically exceeds the available capacity. In the airline industry, overbooking is predominantly used as a hedge against passengers who either cancel or do not claim the seats that they have reserved and by allowing more seats to be booked, the load factor can be improved during takeoff. Historical data has shown that about 10-15\% of passengers do not claim the seats they reserved (Rothstein 1985, USA Today 1998). In the event that more consumers than expected show up, overbooking inevitably leads to overselling. The practice of overselling is highly regulated. Since 1976, the U.S Department of Transportation (DOT) has mandated compensations for involuntary bumping in the form of a free ticket in the future, an upgrade in a subsequent flight, some travel vouchers or even cash ${ }^{4}$. As an officially sanctioned practice of over forty years, the popularity of deliberate selling beyond the available capacity continues unabated. Furthermore, the improvement in data collection technology has motivated scores of companies to explore innovative pricing strategies to maximize revenue in the face of differentiated consumers. While overselling seemingly provides a "win-win" scenario for the firm and the consumer, its impact on firms' profitability remains interesting and relevant. With large amount of data available for industry-assist opportunities, this work explores the value of overbooking (and overselling) where tactical rules are prescribed for determining the "right" price and the "right" capacity allocation in the face of demand variability driven by consumers' erratic behaviors over the selling periods.

Our work straddles within operations research, economics and marketing that deals with managing demand uncertainty (Philips 2005, Talluri and van Ryzin 2004, Bitran and Caldentey 2003, Elmaghraby and Keskinocak 2003 and Weatherford and Bodily 1992 all provide good overviews in this area). With our goal to investigate tactical allocation of fixed capacity, this research is closely related to the area of price-based revenue management. For the monopolist, Wilson (1988) showed that firms can increase profits by charging two different prices and rationing sales at discount. Furthermore, Dana (1999) showed that demand uncertainty is sufficient to create price dispersion when consumers are differentiated by timing preferences. Fedegruen and Heching (1999) and van

\footnotetext{
${ }^{4}$ see http://airconsumer.dot.gov/publications/flyrights.htm\#overbooking
} 
Meighem and Dada (1999) in particular, examined the role of inventory in managing pricing competition when there is demand uncertainty. For the monopolist, Shugan and Xie (2000) found that uncertainty in buyers' valuation are sufficient to drive profitability for advance selling. Later, Shugan and Xie (2005) extended advance selling to a competitive framework and they showed that profitability of both firms increases. It turns out that while discount seeking buyers are targeted parties for advance selling, the additional volume more than compensates for the discount. However, these models do not consider overbooking.

The seminal work of Rothstein (1971) studied overbooking and derived an algorithm to determine the extent of overbooking while Desiraju and Shugan (1999) investigated overbooking as part of an yield management system when there are cancellations. Even if consumers do not skip reservations, Biyalogorsky et al. (1999) showed that overselling with opportunistic cancellation is always profitable for a monopolist, as long as the late-arriving consumers value the ticket more than early-arriving ones. With the same model setup, Lim (2009) extended it to a duopoly and showed that overselling is a weakly dominant strategy although the outcome where both firms oversell may not always be Pareto-dominant. In fact, the work of Lim (2009) formally validates the popular belief that overselling drives the "win-win" scenario: the valuation of late-arrivals is sufficiently high making it feasible for firms to extract the reselling premium after compensating bumped consumers. However, the key assumption that drive these results is that demand from early arrivals exceeds both firms' capacities and thus void the market of any pricing competition or negative impact of demand uncertainty. In reality, this may not always be the case, albeit consumers who arrive early are commonly deemed to have a lower valuation than those who arrive late (Desiraju and Shugan 1999). During the financial crisis in 2008, the overall reduction in travel demand resulted in under-utilized capacities and forced major airlines to ground some of their flights (The China Post 2009)! When early period demand turns out to be stochastic, the deliberate intention of selling beyond its capacity may fail to happen, undermining the potential of this practice as a hedge against consumers' no-show. In a related work, Netessine and Shumsky (2005) considered the equilibrium allocation of seat capacity between fare classes and booking limits when firms compete under the same price points. Recently, Sierag et al (2015) propose a revenue management model that takes 
into account of cancellations and customer choice behaviour. Using models to calibrate the parameters, they design efficient heuristic solution methods to optimize revenue. Finally, Lan et al (2015) investigate a single-leg airline revenue management problem where an airline uses limited demand information and uncensored no-show information to develop booking control decisions, resulting in the seminal work that of seat allocation and overbooking decisions with such hybrid information. With genuine pricing competition introduced by demand uncertainty in practice, these works did not address the value of overselling within the context of revenue management.

Our work examines joint capacity allocation and pricing strategies whose consumers are differentiated by timing of their arrivals, i.e., early and late arriving consumers. Frequently touted as the airline industry's best practice, we further seek to understand the value (and role) of voluntary bumping with two selling options for the firm; namely, the conventional selling strategy $(C S)$ and the overselling strategy $(O S)$. We define a conventional selling strategy as one whereby goods contracted to early consumers are not resold to late (albeit high valuation) consumers. This is reflective of not bumping away consumers even if market condition is favorable for reselling, for e.g., demand by late arriving consumers exceeds quantities available for sale during that period. In contrast, we define overselling strategy as one whereby a firm bumps but compensates its early consumers in the process of reselling all previously contracted units. Under revenue maximization, we posit that the value of overselling could have been overstated in reality and is dependent on market structure. Should the monopolist refrain from bumping away consumers in anticipation of weak selling opportunity during the early period? In a similar vein, we provide answers that should interest the majority of firms operating under intense competition: "Can an equilibrium be sustained when one firm finds it profitable to refrain from overselling even when its competitor oversells?" or "Can an equilibrium exist where none of the firms oversells?" More specifically, we analyze the underlying forces driving the equilibrium selling strategies and consider the feasibility of overselling as a best response for the firms operating in a duopoly regime.

Our research yields the following policy insights and implications. First, overselling remains profitable for the monopolist whenever it is possible to obtain reselling premium, a principle that continues to hold even when demand is uncertain in the early period. Second, we show it is not 
true that when both firms oversell, their actions necessarily constitutes an equilibrium. This is in contrast with the results in Lim (2009) and thus, generality of previous findings do not extend in a duopoly once early demand is limited. Our research debunks earlier works that found overselling to be weakly dominant and further raises a word of caution against practitioners' complacency in regarding it as a foolproof hedging strategy. Third, and more importantly, our results show that when early demand is limited, there exist multiple equilibria when allocating capacity and this leads to the outcome whereby the same parameters on demand arrivals, firm capacities and consumer valuations can result in different selling strategies at the equilibrium. In other words, in addition to market conditions and firm characteristics, the co-ordination between firms at the inventory allocation level also has a part to play in determining the selling strategies at the equilibrium.

The main contribution of our paper is two-fold. Firstly, this is the first paper that established that once the assumption of an unlimited early demand ceases to hold, existing findings about overselling as a (weakly) dominant strategy may no longer hold. This is because overselling necessarily means that the available capacity is magnified and thus intensifies the pricing competition between the firms in both periods. Thus, this paper extends our understanding of the overselling policy that is prevalent in practice, yet we have limited appreciation of the intricacies involved once early demand is limited. In addition, we also illustrate that simply having a compensation level that is less than the valuation of the late-arriving consumer is not sufficient to guarantee that overselling is indeed a (weakly) dominant strategy, again, contrary to earlier findings. When early demand is not high, pricing competition between the firms are intensified. In this case, the profit margin of selling to a late-arriving consumer has to be much higher than the compensation needed.

The rest of the paper is organized as follows. In $\S 2$, we present the stylized model. In $\S 3$, we examine the case of the monopoly seller. In $\S 4$, we focus on duopoly. In particular, we analyze the joint capacity allocation and pricing equilibrium strategies and finally, we derive the equilibrium selling strategies for the firm. Some numerical examples are provided to illustrate our findings. We conclude in $\S 5$. 


\section{The Model}

In this section, we present a stylized model that examines the role of overselling in a two-period competitive environment with demand uncertainty over both periods. ${ }^{5}$ Furthermore, as representative of industries where the overselling strategy is a common practice, our model examines goods (we use the term goods to refer to both products and services) that exhibit the following characteristics. First, the good is perishable and is considered to be of value only for a limited time period. More specifically, we assume that the salvage value of the good is zero at the end of Period 2. Second, the good can be bought in advance either during Periods 1 or 2 but consumption takes place only at the end of Period 2 just before the salvage value of the good diminishes to zero. Third, the marginal cost of production of the good is negligible as long as it is within the capacity, which is fixed and cannot be adjusted in the short term. Fourth, the good is non-transferable. Examples include most goods in the travel industry, such as air tickets, hotel bookings as well as medical appointments and the selling of media slots. However, our model does not include goods such as concert tickets or World Cup tickets which are transferable and thus have the potential to spin off secondary markets where speculators buy the good in anticipation of making a hefty profit from reselling it ( $\mathrm{Su} 2009$, Lim and Tang 2010). Goods of this nature are beyond the scope of this paper. Throughout, we will assume that there is no possibility of no show. However, it will become apparent that the essence of our results remain unchanged even if we relax this assumption.

Specification of the Game: We consider a model whereby early consumers with valuation $v_{1}$ arrive in Period 1 while late consumers with valuation $v_{2}$ arrive in Period 2 and $v_{2}>v_{1}{ }^{6}$. It is widely accepted that late arriving consumers are generally business travellers with corporate accounts and thus have a higher valuation than the early consumers (see Desiraju and Shugan 1999). For simplicity, we assume that the consumers have the same valuation for the goods provided by both firms. To capture demand uncertainty, let $X_{t}$ be the random variable for the number of consumers who arrive in Period $t$ for $t=1,2$. We assume that the timing of the consumer's arrival is exogenous

\footnotetext{
${ }^{5}$ The monopoly model is a special case of the duopoly model and we omit its description here. The analysis though, is given in $\S 3$.

${ }^{6}$ For ease of exposition, we have included a summary table of notations in the Appendix, see page 28.
} 
and early arriving consumers are not forward looking, i.e., they do not delay their purchase decisions until Period 2. We further assume that early consumers who did not buy the good will leave forever to seek alternatives. This is a reasonable assumption as holiday makers who do not manage to get an air ticket to a destination will change to another destination. An alternative interpretation is that early consumers who do not manage to buy in the early period but choose to return in Period 2 are considered as late consumers and the persistence on their part is reflected by a higher valuation in the late period. ${ }^{7}$ Furthermore, let us denote $N_{i}$ to be the capacity for Firm $i$ where price is set based on its respective allocation strategy. In general, advance disclosure on the available number of units for sale before firms set their respective prices is a reasonable assumption since there are various websites that provide such information at any point in time ${ }^{8}$. The interplay between capacity and price can be summarized as follows. We assume that consumers are extremely price-sensitive and will purchase from the firm that offers the lowest price. These consumers switch whenever (1) there exists some competitor that is able to offer a lower price and (2) capacity offered by the lowest price firm has been exhausted.

Sequence of Event: Our multiple-period dynamic game with observed actions can be specified as follows. To focus on the impact of selling strategies on pricing and capacity allocation, we simplify our analysis by allowing $N_{A}=N_{B}=N$ to be the common capacity for both firms.

Period $\boldsymbol{0}$. We denote the action space of Firm $i$ to be $\{C S, O S\}$. Firms $A$ and $B$ simultaneously decide on their selling strategies $\lambda_{A}, \lambda_{B}\left(\lambda_{i} \in\{C S, O S\}, i=A, B\right)$. As such, the set of pure strategy profiles $S=\left\{\left(\lambda_{A}, \lambda_{B}\right)\right\}$ consists of four possibilities: (CS, CS ), (CS,OS), (OS,CS) and $(O S, O S)$. Subsequently, Firms $A$ and $B$ simultaneously determine the number of units $k_{A}\left(\lambda_{A}, \lambda_{B}\right), k_{B}\left(\lambda_{A}, \lambda_{B}\right)$ to allocate for sale in Period 1 while the remaining $\left(N-k_{A}\left(\lambda_{A}, \lambda_{B}\right)\right),\left(N-k_{B}\left(\lambda_{A}, \lambda_{B}\right)\right)$ units will be reserved for sale in Period 2.

Period 1. Firms $A$ and $B$ simultaneously set prices $p_{A, 1}\left(\lambda_{A}, \lambda_{B}\right), p_{B, 1}\left(\lambda_{A}, \lambda_{B}\right)$ to maximize their revenue after observing selling strategies $\lambda_{A}, \lambda_{B}$ and capacity allocations $k_{A}\left(\lambda_{A}, \lambda_{B}\right), k_{B}\left(\lambda_{A}, \lambda_{B}\right)$.

\footnotetext{
${ }^{7}$ This assumption is consistent with Biyalogorsky et al. (1999) and Lim (2009). In addition, when $v_{2}$ is sufficiently larger than $v_{1}$, the price in Period 2 is higher than that in Period 1 so there is no incentive for early consumers to delay their purchase till Period 2.

${ }^{8}$ For e.g., http://www.expertflyer.com and http://www.seatcounter.com
} 
During this period, $X_{1}$ early consumers arrive and make their purchase decisions after observing prices set by the firms. In general, the consumer purchases from Firm $i$ in Period $t$ if and only if (1) there is available capacity, and (2) $p_{i, t}\left(\lambda_{A}, \lambda_{B}\right)=\min \left(p_{A, t}\left(\lambda_{A}, \lambda_{B}\right), p_{B, t}\left(\lambda_{A}, \lambda_{B}\right)\right) \leq v_{t}$. If there is insufficient capacity to support consumer demand, then consumers will switch and purchase from its competitor, otherwise the consumer leaves the market. ${ }^{9}$ To determine actions in the last period, it is necessary to see how early demand for Firm $i$ gets triggered by allocation and pricing decisions:

$$
D_{i, 1}= \begin{cases}\min \left(X_{1}, k_{i}\right), & \text { if } p_{i, 1}<p_{j, 1}, \\ \min \left(\left(X_{1}-k_{j}\right)^{+}, k_{i}\right), & \text { if } p_{i, 1}>p_{j, 1} .\end{cases}
$$

$j \neq i$. Firms A and B earn Period 1 profits $p_{A, 1} D_{A, 1}$ and $p_{B, 1} D_{B, 1}$, respectively. We note that $D_{A, 1}$ and $D_{B, 1}$ are dependent on $k_{A}, k_{B}, p_{A, 1}, p_{B, 1}$ but independent of chosen selling strategies $\lambda_{A}, \lambda_{B}$. As a result of the pricing competition introduced, the available selling capacities for the last period becomes $c_{A}=N-D_{A, 1}$ and $c_{B}=N-D_{B, 1}$.

Period 2. Firms $A$ and $B$ simultaneously set prices $p_{A, 2}\left(\lambda_{A}, \lambda_{B}\right), p_{B, 2}\left(\lambda_{A}, \lambda_{B}\right)$ to maximize their revenue after observing selling strategies $\lambda_{A}, \lambda_{B}$, capacity allocations $k_{A}\left(\lambda_{A}, \lambda_{B}\right), k_{B}\left(\lambda_{A}, \lambda_{B}\right)$ and available selling capacities $c_{A}, c_{B}$. Subsequently, $X_{2}$ consumers arrive and make their purchase decisions upon observing the prices in that period. Figure 1 shows the sequence of events.

To this end, we note that the choice of selling strategy at the start of this game has cascading implications on available selling capacities in Period 2. If Firm $i$ chooses conventional selling, the available selling capacity comes from the reserved $N-k_{i}\left(\lambda_{i}, \lambda_{j}\right)$ units plus unsold units that were meant to target early arriving consumers. ${ }^{10}$ This is driven by stochastic early arrivals where that Firm $i$ may not necessarily exhaust all the allocated $k_{i}\left(\lambda_{i}, \lambda_{j}\right)$ units in Period 1 and those unsold units are naturally available for sale in Period 2. If Firm $i$ chooses overselling, the available selling

\footnotetext{
${ }^{9}$ We assume that if demand is higher than the available supply, the goods are randomly assigned to the consumers. Likewise, if both firms have the same price, demand is uniformly assigned to the firms.

${ }^{10} k_{i}(C S, C S)$ is equivalent to the booking limit $B_{i}$ defined in Netessine and Shumsky (2005). However, our framework includes pricing competition between the firms. More specifically, the demand in Period 1 defined as $X_{1}$ in our model is equals to the demand $D_{L i}+D_{L j}$ in Netessine and Shumsky (2005). Upon announcement of the prices $p_{i, 1}(C S, C S), p_{j, 1}(C S, C S)$ by the firms, if $p_{i, 1}(C S, C S)<p_{j, 1}(C S, C S), D_{L i}=\min \left(k_{i}(C S, C S), X_{1}\right)$, $D_{L j}=X_{1}-D_{L i}$.
} 
capacities in Period 2 includes an additional reselling opportunity that arises from the units already sold in Period 1. However, the firm is obligated to provide a compensation of $\tau\left(>p_{i, 1}\right)$ to the early consumer. ${ }^{11}$ It is thus reasonable to assume that $\tau<v_{2}$, for otherwise, there is no incentive for the firms to resell units that are already sold in Period 1. Finally, it is easy to see that Firm $i$ can only resell up to the number of units sold in Period 1 that is bounded by $k_{i}\left(\lambda_{i}, \lambda_{j}\right){ }^{12}$

\begin{tabular}{lll|} 
Period 0 & \multicolumn{1}{c}{ Period 1} & Period 2 \\
\hline $\begin{array}{l}\text { (1) Firms simultaneously decide on } \\
\text { selling strategies } \lambda_{A}, \lambda_{B} \text {. }\end{array}$ & $\begin{array}{l}\text { (1) Firms simultaneously decide on } \\
\text { prices } p_{A, 1}, p_{B, 1} \cdot\end{array}$ & $\begin{array}{l}\text { (1) Firms simultaneously decide on } \\
\text { prices } p_{A, 2}, p_{B, 2} \cdot\end{array}$ \\
$\begin{array}{ll}\text { (2) Firms simultaneously decide on } \\
\text { allocations } k_{A}, k_{B} \text {. }\end{array}$ & $\begin{array}{l}\text { (2) Early consumers arrive and make } \\
\text { purchase decisions. }\end{array}$ & $\begin{array}{l}\text { (2) Late consumers arrive and make } \\
\text { purchase decisions. }\end{array}$
\end{tabular}

Figure 1: Sequence of Events

\section{The Monopoly Model}

Let us without loss of generality assume that only Firm $i$ exists in the market. Our goal is to ascertain if the monopolist will be better off adopting the overselling strategy when demand arrivals in both periods are uncertain. We write the payoff function under the given selling strategy $\left(\lambda_{i}\right)$ and allocated capacity $\left(k_{i}\right)$. The absence of competition (i.e., $p_{-i, t}=k_{-i}=0$ ) implies that for Firm $i$, the early demand and the observed available selling capacity trivially reduces to $D_{i, 1}=\min \left(X_{1}, k_{i}\right)$

\footnotetext{
${ }^{11}$ We assume that $\tau$ is exogenous so that we can focus on the selling strategies of the firms and need not take into consideration the strategic role of $\tau$. In practice, there is some generally accepted compensation. For example, the U.S. Department of Transport has some general guidelines on the compensation (see http://airconsumer.dot.gov/publications/flyrights.htm\#overbooking). Furthermore, consumers are not known to take $\tau$ into consideration when making their purchase decisions. In the model of Netessine and Shumsky (2005), there is no possibility of bumping, voluntary or otherwise, thus no consideration of the overselling strategy.

${ }^{12}$ In our framework, we do not consider the potential loss of customer goodwill from reselling. However, this assumption does not affect the essence of our results.
} 
and $c_{i}=N-\min \left(X_{1}, k_{i}\right)$, respectively. ${ }^{13}$ Given that $p_{i, t}$ is the price set prior to the realization of $X_{i}$, the payoff for the monopolist can be written as: 14

$$
\begin{aligned}
\Pi_{i}^{C S}\left(k_{i}\right)= & \max _{p_{i, t} \leq v_{t}} p_{i, 1} E\left[N-c_{i}\right]+p_{i, 2} E\left[\min \left(c_{i}, X_{2}\right)\right], \\
\Pi_{i}^{O S}\left(k_{i}\right)= & \max _{p_{i, t} \leq v_{t}} p_{i, 1} E\left[N-c_{i}\right]+p_{i, 2} E\left[\min \left(c_{i}, X_{2}\right)\right]+ \\
& \left(p_{i, 2}-\tau\right) E\left[\min \left(\left[X_{2}-c_{i}\right]^{+}, N-c_{i}\right)\right] .
\end{aligned}
$$

As in the case of all monopolies, Firm $i$ sets price $p_{t}$ to be the consumers valuation $v_{t}$ in Period $t$, $t=1,2$. We can see from the equations above that the expected payoff for the firm when it adopts the overselling strategy is simply what it gets by adopting the conventional selling strategy plus the expected payoff it can achieve by reselling, which is given as the last term in (2). One immediate consequence is that if the number of units allocated to Period 1, as denoted by $k_{i}$ here, is the same under both selling strategies, then clearly, adopting the overselling strategy is no less profitable for the monopoly firm.

\subsection{Optimal Allocation Rule and Selling Strategy}

To understand the impact of selling strategies for the monopolist Firm $i$, we first examine the optimal allocation rule, i.e., the optimum number of units $k_{i}$ to allocate to Period 1 , and thus, the remaining units $\left(N-k_{i}\right)$ for Period 2. If we use $k_{\lambda_{i}}^{*}$ to denote the optimum number of units allocated for Period 1 when the firm adopts the selling strategy $\lambda_{i}\left(\lambda_{i} \in\{C S, O S\}\right)$. Then it must be necessary that $k_{C S}^{*}, k_{O S}^{*}(\leq N)$ are the largest integer such that $\Pi^{C S}\left(k_{C S}^{*}\right)-\Pi^{C S}\left(k_{C S}^{*}-1\right)>0$ and $\Pi^{O S}\left(k_{O S}^{*}\right)-\Pi^{O S}\left(k_{O S}^{*}-1\right)>0$, which simplify to

$$
\begin{aligned}
& v_{1}>v_{2} P\left(X_{2} \geq N-k_{C S}^{*}+1 \mid X_{1} \geq k_{C S}^{*}\right), \\
& v_{1}>\tau P\left(X_{2} \geq N-k_{O S}^{*}+1 \mid X_{1} \geq k_{O S}^{*}\right) .
\end{aligned}
$$

Conventional Selling. The allocation rule spells out the tradeoff in allocating the unit between Period 1 and reserving it for Period 2. When the $k_{C S}^{*}$-th unit can be sold with positive probability

\footnotetext{
${ }^{13}$ Since there is only a monopoly firm in this section, we omit the subscript for the firm.

${ }^{14}$ The selling strategy adopted by the firm is denoted by the superscripts in the expected profit function.
} 
in Period 1, the value of not reserving it for deferred selling can be understood by rewriting (3):

$$
v_{1} P\left(X_{2}<N-k_{C S}^{*}+1 \mid X_{1} \geq k_{C S}^{*}\right)>\left(v_{2}-v_{1}\right) P\left(X_{2} \geq N-k_{C S}^{*}+1 \mid X_{1} \geq k_{C S}^{*}\right) .
$$

Given that $P\left(X_{1} \geq k_{C S}^{*}\right)>0$, there is no value in reserving the $k_{C S}^{*}$-th unit when the payoff $v_{1}$ obtained from locking in the early selling opportunity is greater than the premium obtained from deferred selling, subjected to the firm's ability to sell it.

Overselling. The extent of overselling characterized by the number of early consumers to bump in favour of reselling premium presents similar tradeoff. To understand the value of reselling the $k_{O S}^{*}$-th unit, we rewrite (4):

$$
v_{1} P\left(X_{2}<N-k_{O S}^{*}+1 \mid X_{1} \geq k_{O S}^{*}\right)>\left(\tau-v_{1}\right) P\left(X_{2} \geq N-k_{O S}^{*}+1 \mid X_{1} \geq k_{O S}^{*}\right) .
$$

In a similar vein, the value of overselling the $k_{O S}^{*}$-th unit is undermined when the payoff obtained from locking in early sales opportunity exceeds the reselling premium $\tau-v_{1}$ captured in Period 2. We argue that the monopolist that engages in overselling is relatively more risk-averse. First, a unit can always be resold in Period 2 as long as the demand arrival in Period 2 warrants it under the overselling strategy. Second, the opportunity cost of forgoing the deferred selling payoff $v_{2}$ (by adopting $C S$ ) is higher than the cost of attempt in enabling the resell opportunity $\tau$ (by adopting $O S$ with reselling premium $\left.v_{2}-\tau\right)$. As $v_{2}>\tau$ implies that $\Pi^{O S}\left(k_{C S}^{*}\right)>\Pi^{O S}\left(k_{C S}^{*}-1\right)$, we have $k_{C S}^{*} \leq k_{O S}^{*}$ since by definition of $k_{O S}^{*}$. Furthermore, we note that since $\Pi^{C S}\left(k_{C S}^{*}\right) \leq \Pi^{O S}\left(k_{C S}^{*}\right) \leq$ $\Pi^{O S}\left(k_{O S}^{*}\right)$, a monopoly firm is always better off overselling. Therefore, we have the following result.

Theorem 1 The number of units that a monopoly firm allocates for Period 1 when it adopts the overselling strategy is no less than the number of units it allocates for Period 1 if it adopts the conventional selling strategy, i.e., $k_{O S}^{*} \geq k_{C S}^{*}$ if the arrivals $X_{1}, X_{2}$ are independent. The monopolist always optimally oversells whenever $v_{2}>\tau$.

When a firm operates in a monopoly market, it is able to fix the price at the consumer's valuation in each period, doing away with any price competition. Hence, it is not surprising that a monopoly firm is always better off overselling. More importantly, the result holds under general demand arrivals $X_{1}, X_{2}$, requiring only that the valuation of late-arriving consumers exceeds the sum of 
the refund and compensation for reselling. However, in the presence of competition in a duopoly, price competition between the firms makes the tradeoff between allocating a unit for Period 1 and reserving it for Period 2 more complex and less straightforward, particularly so when the demand arrival in Period 1 is also stochastic and not sufficiently high to avoid pricing competition. In the following section, we focus on the duopoly market and determine the optimum allocation rule and the selling strategies at the equilibrium.

\section{The Duopoly Model}

We use subgame perfection as our solution concept and apply backward induction to solve for the equilibrium. We will first consider the pricing strategies and optimum capacity allocation rules in each of the three subgames, namely when both firms adopt the conventional selling strategy $\left(\left(\lambda_{A}, \lambda_{B}\right)=(C S, C S)\right)$, when both firms adopt the overselling strategy $\left(\left(\lambda_{A}, \lambda_{B}\right)=(O S, O S)\right)$, and when only one firm, say Firm $i$, adopts the conventional selling strategy while Firm $j$ adopts the overselling strategy $\left(\left(\lambda_{i}, \lambda_{j}\right)=(C S, O S)\right), i, j=A, B, i \neq j$. Unless there is a possibility of confusion, we will omit the term $\left(\lambda_{A}, \lambda_{B}\right)$ in our notations in the following subsection.

\subsection{Period 2 Pricing Equilibrium}

Given selling strategies $\lambda_{A}, \lambda_{B}$ and remaining capacities $c_{A}, c_{B}$, Firms $A$ and $B$ compete on prices in Period 2. As in Narasimhan (1988), we will informally argue that the equilibrium pricing strategy in Period 2 must necessarily be a mixed strategy (the formal proof is given in the appendix). ${ }^{15}$ Since our model assumes that the consumer's valuation for the firms' goods are identical, consumers buy from the firm with the lower price. This purchasing behavior of the consumers results in intense price competition for the firms, with each of them trying to undercut the other firm, until the point where the price is at zero, at which point, a firm is better off increasing its price to the valuation $v_{2}$ for otherwise, the expected profit is zero anyway. This is because the uncertainty in demand arrival implies that a small reduction in price can trigger a significant increase in sales volume while compromising only a minute profit margin as long as capacity is sufficiently large relative to

\footnotetext{
${ }^{15}$ The set of mixed strategies includes the pure strategies that are degenerate mixed strategies.
} 
demand. In response to this, the competing firm will be better off setting a price of $\left(v_{2}-\epsilon\right)$, where $\epsilon$ is a small positive number. Again, this will trigger another round of price cuts. For $i \in\{A, B\}$, let us denote $p_{i, 2}$ and $p_{-i, 2}$ to be the prices chosen by Firm $i$ and its competitor, respectively. Given the chosen selling strategies $\lambda_{i}$ and realized remaining capacity $c_{i}$, the payoff for Firm $i$ during Period 2 as a result of its undercutting effort can be derived as follows.

Firm Undercuts. Suppose $p_{i, 2}<p_{-i, 2}$, the payoff for Firm $i$ can be written as

$$
\Pi_{i, 2}\left(p_{i, 2}, p_{-i, 2}, c_{i}, c_{-i}, \lambda_{i}, \lambda_{-i}\right)=p_{i, 2} \hat{\phi}_{i}+\left(p_{i, 2}-\tau\right) \hat{\rho}_{i}
$$

where $\hat{\phi}_{i}=E\left[\min \left(X_{2}, c_{i}\right)\right]$ and

$$
\hat{\rho}_{i}= \begin{cases}0, & \text { if } \lambda_{i}=C S \\ E\left[\min \left(\left(X_{2}-c_{i}\right)^{+}, N-c_{i}\right)\right], & \text { if } \lambda_{i}=O S\end{cases}
$$

When Firm $i$ undercuts its competitor, the pricing game results in its payoff $\Pi_{i, 2}\left(p_{i, 2}, p_{-i, 2}, c_{i}, c_{-i}, \lambda_{i}, \lambda_{-i}\right)$ being independent of its competitor's selling strategy. The definition of $\hat{\rho}_{i}$ implies that the value of overselling comes from late arrivals $X_{2}$ exceeding the available selling capacity $c_{i}$ during this period and is constrained by the limited available opportunity $N-c_{i}$ for overselling.

Firm Does Not Undercut. Suppose we have $p_{i, 2}>p_{-i, 2}$, the payoff for Firm $i$ becomes $\Pi_{i, 2}\left(p_{i, 2}, p_{-i, 2}, c_{i}, c_{-i}, \lambda_{i}, \lambda_{-i}\right)=p_{i, 2} \phi_{i}+\left(p_{i, 2}-\tau\right) \rho_{i}$, where

$$
\begin{gathered}
\phi_{i}= \begin{cases}E\left[\min \left(\left(X_{2}-c_{-i}\right)^{+}, c_{i}\right)\right], & \text { if } \lambda_{-i}=C S ; \\
E\left[\min \left(\left(X_{2}-N\right)^{+}, c_{i}\right)\right], & \text { if } \lambda_{-i}=O S .\end{cases} \\
\rho_{i}= \begin{cases}0, & \text { if } \lambda_{i}=C S ; \\
E\left[\min \left(\left(X_{2}-c_{-i}-c_{i}\right)^{+}, N-c_{i}\right)\right], & \text { if } \lambda_{i}=O S, \lambda_{-i}=C S ; \\
E\left[\min \left(\left(X_{2}-N-c_{i}\right)^{+}, N-c_{i}\right)\right], & \text { if } \lambda_{i}=O S, \lambda_{-i}=O S .\end{cases}
\end{gathered}
$$

Without engaging in price undercutting, Firm $i$ 's payoff now become dependent upon the selling strategy of its competitor. In this case, the demand for Firm $i$ are primarily driven by late consumers (not supported by its competitor due to finite capacity) and $\rho_{i}$ implies that overselling loses its shine whenever the number of firms adopting $O S$ increases. Observe that $\hat{\phi}_{i} \geq \phi_{i}$ and $\hat{\rho}_{i} \geq \rho_{i}$ for $i \in\{A, B\}$. Moreover, unless $\lambda_{-i}=C S$ and $c_{-i}=0, \hat{\phi}_{i}>\phi_{i}$. Similarly, unless $\lambda_{i}=C S$, or 
$\lambda_{i}=O S, \lambda_{-i}=C S$ and $c_{-i}=0, \hat{\rho}_{i}>\rho_{i}$. The following result is critical to establishing the pricing strategy in Period 2.

Lemma 1 If Firm $i$ adopts selling strategy $\lambda_{i}$, then it is able to sell more units if it undercuts the price set by its competitor.

Essentially, Lemma 1 says that price undercutting as a tool is effective in driving additional sales irregardless of selling strategy, except for trivial cases where there is no price competition. As a result, the equilibrium pricing strategy in Period 2 must necessarily be a mixed strategy for each firm. To present the Period 2 pricing equilibrium result, we define for each $i \in\{A, B\}$,

$$
l_{i, 2}=\frac{v_{2}\left(\phi_{i}+\rho_{i}\right)+\tau\left(\hat{\rho}_{i}-\rho_{i}\right)}{\hat{\phi}_{i}+\hat{\rho}_{i}}, i_{2}^{*}=\arg \max _{i \in\{A, B\}}\left\{l_{i, 2}\right\}, \quad l_{2}=\max _{i \in\{A, B\}}\left\{l_{i, 2}\right\} .
$$

Theorem 2 Suppose the selling strategies are $\left(\lambda_{A}, \lambda_{B}\right)$ and the remaining capacities are $c_{A}$ and $c_{B}$. The second period Nash equilibrium pricing strategy is a mixed pricing strategy characterized by $\sigma_{i_{2}^{*}}(y)$, the probability that Firm $i_{2}^{*}$ chooses $p_{i_{2}^{*}, 2}$ to be less than or equal to $y \in\left[l_{2}, v_{2}\right]$, and $\sigma_{-i_{2}^{*}}(y)$, the probability that Firm $-i_{2}^{*}$ chooses $p_{-i_{2}^{*}, 2}$ to be less than or equal to $y \in\left[l_{2}, v_{2}\right)$. The equilibrium profits in Period 2 are given by $\Pi_{A, 2}^{*}\left(c_{A}, c_{B}, \lambda_{A}, \lambda_{B}\right)=l_{2} \hat{\phi}_{A}+\left(l_{2}-\tau\right) \hat{\rho}_{A}$ and $\Pi_{B, 2}^{*}\left(c_{A}, c_{B}, \lambda_{A}, \lambda_{B}\right)=$ $l_{2} \hat{\phi}_{B}+\left(l_{2}-\tau\right) \hat{\rho}_{B}$, where $\hat{\phi}_{i}, \hat{\rho}_{i}, l_{2}$.

\subsection{Period 1 Pricing Equilibrium}

We can now analyze the pricing game in Period 1 taking into consideration expected future equilibrium payoffs in Period 2 obtained in the previous section. Given selling strategies $\left(\lambda_{A}, \lambda_{B}\right)$ and Period 1 capacity allocations $\left(k_{A}, k_{B}\right)$, firms play a pricing game by choosing prices $\left(p_{A, 1}, p_{B, 1}\right)$ with the expected profits

$$
\Pi_{i, 1}\left(p_{i, 1}, p_{-i, 1}, \lambda_{A}, \lambda_{B}\right)= \begin{cases}p_{i, 1} \hat{\eta}_{i}+\hat{Z}_{i}, & \text { if } p_{i, 1}<p_{-i, 1} \\ p_{i, 1} \eta_{i}+Z_{i}, & \text { if } p_{i, 1}>p_{-i, 1}\end{cases}
$$


where

$$
\begin{aligned}
& \hat{Z}_{A}=E\left[\Pi_{A, 2}^{*}\left(N-\min \left(X_{1}, k_{A}\right), N-\min \left(\left(X_{1}-k_{A}\right)^{+}, k_{B}\right), \lambda_{A}, \lambda_{B}\right)\right], \\
& Z_{A}=E\left[\Pi_{A, 2}^{*}\left(N-\min \left(\left(X_{1}-k_{B}\right)^{+}, k_{A}\right), N-\min \left(X_{1}, k_{B}\right), \lambda_{A}, \lambda_{B}\right)\right], \\
& \hat{Z}_{B}=E\left[\Pi_{B, 2}^{*}\left(N-\min \left(\left(X_{1}-k_{B}\right)^{+}, k_{A}\right), N-\min \left(X_{1}, k_{B}\right), \lambda_{A}, \lambda_{B}\right)\right], \\
& Z_{B}=E\left[\Pi_{B, 2}^{*}\left(N-\min \left(X_{1}, k_{A}\right), N-\min \left(\left(X_{1}-k_{A}\right)^{+}, k_{B}\right), \lambda_{A}, \lambda_{B}\right)\right],
\end{aligned}
$$

are functions of $k_{A}, k_{B}, \lambda_{A}$ and $\lambda_{B}$, whereas

$$
\hat{\eta}_{i}=E\left[\min \left(X_{1}, k_{i}\right)\right], \eta_{i}=E\left[\min \left(\left(X_{1}-k_{-i}\right)^{+}, k_{i}\right)\right] .
$$

for each $i \in\{A, B\}$, are functions of $k_{A}$ and $k_{B}$ but independent of $\lambda_{A}$ and $\lambda_{B}$. During Period 1, the undercutting effort continues to help the firm capture larger market share plus the equilibrium payoff generated during the subsequent selling period. To present the Period 1 pricing equilibrium result, we define for each $i \in\{A, B\}$,

$$
l_{i, 1}=\frac{v_{1} \eta_{i}+Z_{i}-\hat{Z}_{i}}{\hat{\eta}_{i}}, \quad i_{1}^{*}=\arg \max _{i \in\{A, B\}}\left\{l_{i, 1}\right\}, \quad l_{1}=\max _{i \in\{A, B\}}\left\{l_{i, 1}\right\} .
$$

Theorem 3 Suppose the selling strategies are $\left(\lambda_{A}, \lambda_{B}\right)$ and capacity allocations are $k_{A}$ and $k_{B}$. The first-period equilibrium pricing strategy is a mixed pricing strategy characterized by $\omega_{i_{2}^{*}}(y)$, the probability that Firm $i_{1}^{*}$ chooses $p_{i_{1}^{*}, 1}$ to be less than or equal to $y \in\left[l_{1}, v_{1}\right]$, and $\omega_{-i_{1}^{*}}(y)$, the probability that Firm $-i_{1}^{*}$ chooses $p_{-i_{1}^{*}, 1}$ to be less than or equal to $y \in\left[l_{1}, v_{1}\right)$. The equilibrium payoffs are given by $\Pi_{A, 1}^{*}\left(k_{A}, k_{B}, \lambda_{A}, \lambda_{B}\right)=l_{1} \hat{\eta}_{A}+\hat{Z}_{A}$ and $\Pi_{B, 1}^{*}\left(k_{A}, k_{B}, \lambda_{A}, \lambda_{B}\right)=l_{1} \hat{\eta}_{B}+\hat{Z}_{B}$, where $\hat{Z}_{A}, \hat{Z}_{B}, \hat{\eta}_{i}, l_{1}$ are given in (7) and (9), (11), (12).

\subsection{Capacity Allocation Rule and Selling Strategies at Equilibrium: A Numer- ical Illustration}

Here, we will first examine the capacity allocations $k_{A}, k_{B}$ before we determine the selling strategies at equilibrium. In the spirit of backward induction, we can deduce the allocations $k_{A}, k_{B}$ by considering the expected profits of the firms as given in Theorems 2 and 3. The key idea is to compare the expected profits of Firm $i$ when allocating the $k$ th unit for Period 1 or reserving it for 
Period 2 for each of the subgame $\left(\lambda_{A}, \lambda_{B}\right)$ when Firm $j$ allocates $k_{j}$ in Period 1 . Put differently, by comparing the tradeoffs that Firm $i$ faces with the allocation of the $k$ th unit, one would be able to deduce if it is more profitable for the firm to reserve it for Period 2 or to put it up for sale in Period 1. In the appendix, we present the technical result for the special case of symmetric equilibrium. For the general case, the analysis proves unwieldy to be further simplified. As such, we proceed with two numerical examples here to illustrate the underlying intuitions regarding the firms' allocation strategies and selling strategies at equilibrium ${ }^{16}$.

Example 1 (Demand Low Relative to Capacity). Consider two symmetric firms such that $v_{1}=1, v_{2}=2, \tau=1.1$ and $N=2$. Let $X_{1}, X_{2}$ be independent and $X_{t} \sim U[0,2]$ for $t=1,2$. In Tables 1, 2 and 3, we show the allocation game that is faced by the firms in the subgames $(C S, C S)$, $(O S, O S)$ and $(C S, O S)$, respectively. We first note that in this example, each firm has sufficient capacity $(N=2)$ to meet the demand $(\leq 2)$ in each period. This suggests that Example 1 deals with the context where the total demand is relatively low with respect to the capacity available in the market.

When both firms adopt the conventional selling strategy, we can see from Table 1 that the allocation at equilibrium are $\left(k_{A}, k_{B}\right)=(2,1)$ or $(1,2) \cdot{ }^{17}$ That is, one firm allocates its entire capacity to Period 1 (with some chance that not all units can indeed be sold) while the other firm allocates one unit to Period 1 and the remaining unit to Period 2. In this case, owing to both firms adopting the conventional selling strategy, the firm that "focuses" on the market in Period $1\left(k_{i}=2\right)$ does not get any chance to sell any units in Period 2 once its capacity is sold entirely in Period 1, unlike Firm $j$ with $k_{j}=1$. Hence, we observe that Firm $i$ has a lower expected profit than Firm $j(1.67<1.85)$. When both firms adopt the overselling strategy, the relatively low demand with respect to the firms' capacities results in the firms' expected profits being strictly lower than when both firms adopt the conventional selling strategy for all allocations $k_{i}, k_{j}$ when $\max \left(k_{i}, k_{j}\right)>0$. At the equilibrium, $\left(k_{A}, k_{B}\right)=(2,0)$ or $(0,2)$, i.e., one firm again "focuses" on Period 1 while the other on Period 2. As both firms adopt the overselling strategy, the firm focusing on Period 1 has

\footnotetext{
${ }^{16}$ These two numerical examples are presented as they are representative of a range of numerical examples that we have examined.

${ }^{17}$ We focus only on pure-strategy equilibrium at the allocation level.
} 


\begin{tabular}{|c|c|c|c|}
\hline$k_{A} \backslash k_{B}$ & 0 & 1 & 2 \\
\hline 0 & $(0.44,0.44)$ & $(1.33,1.47)$ & $(1.78,1.4)$ \\
1 & $(1.47,1.33)$ & $(1.44,1.44)$ & $\underline{(1.85,1.67)}$ \\
2 & $(1.4,1.78)$ & $\underline{(1.67,1.85)}$ & $(1.78,1.78)$ \\
\hline
\end{tabular}

Table 1: Allocation Game for (CS,CS) in Example 1

\begin{tabular}{|c|c|c|c|}
\hline$k_{A} \backslash k_{B}$ & 0 & 1 & 2 \\
\hline 0 & $(0.44,0.44)$ & $(0.93,1.11)$ & $\underline{(1.18,1.32)}$ \\
1 & $(1.11,0.93)$ & $(0.78,0.78)$ & $(0.99,0.78)$ \\
2 & $\underline{(1.32,1.18)}$ & $(0.78,0.99)$ & $(0.44,0.44)$ \\
\hline
\end{tabular}

Table 2: Allocation Game for (OS,OS) in Example 1

the advantage of reselling (in Period 2) some of its capacity already sold in Period 1, much as the likelihood is low due to the tight demand. Nonetheless, this results in the firm having a higher expected profit than the firm focusing on Period $2(1.32>1.18)$. Finally, it is worthwhile to note that when only one firm (Firm $i$ ) oversells, each firm enjoys a strictly higher expected profit than when both oversell as long as $k_{i}$ is strictly positive. Furthermore, the allocation at the equilibrium in the subgame $(C S, O S)$ is $k_{i}=k_{j}=2$. This suggests that with Firm $i$ adopting the conventional selling strategy, the pricing competition in Period 2 is limited, thereby resulting in higher expected profits for both firms. This allocation game provides some hints into why the overselling strategy may not be a weakly dominant strategy in the face of limited demand in Period 1.

In the following, we derive the selling strategies at equilibrium. Suppose Firm $i$ adopts the conventional selling strategy. If Firm $j$ responds with a conventional selling strategy, its expected profit is either 1.67 or 1.85. If it responds with an overselling strategy instead, its expected profit is $2.22(>1.85>1.67)$ (Table 3). Thus, the best response for Firm $j$ here is to oversell. On the other hand, if Firm $i$ adopts the overselling strategy, Firm $j$ 's expected profit is 1.78 from a conventional selling strategy (Table 3) but 1.18 or 1.32 from an overselling strategy (Table 2). Therefore, the best 


\begin{tabular}{|c|c|c|c|}
\hline$k_{A} \backslash k_{B}$ & 0 & 1 & 2 \\
\hline 0 & $(0.44,0.44)$ & $(0.93,1.11)$ & $(1.18,1.32)$ \\
1 & $(1.47,1.33)$ & $(1.53,1.54)$ & $(1.52,1.54)$ \\
2 & $(1.4,1.78)$ & $(1.67,2.01)$ & $\underline{(1.78,2.22)}$ \\
\hline
\end{tabular}

Table 3: Allocation Game for (CS,OS) in Example 1

\begin{tabular}{|c|c|c|}
\hline$\lambda_{A} \backslash \lambda_{B}$ & CS & OS \\
\hline CS & $(1.85,1.67)$ & $\underline{(1.78,2.22)}$ \\
OS & $\underline{(2.22,1.78)}$ & $(1.18,1.32)$ \\
\hline
\end{tabular}

Table 4: Selling Strategy Game in Example 1

response to an overselling competitor is to adopt the conventional selling strategy. Summarizing, the unique equilibrium at the selling strategy level is for only one firm to oversell. Table 4 shows an instance of the game at the selling strategy level when specific equilibria are chosen at the allocation level for the various subgames. ${ }^{18}$

This example clearly illustrates that overselling may not be (weakly) dominant anymore once the demand in Period 1 is not sufficiently large to accommodate the total capacity of the firms. The intuition is as follows. When the early demand is not sufficiently large to meet the total capacity available, the tradeoffs between allocating units between Periods 1 and 2 become more complex. In particular, the above example shows that when one firm oversells, the best response is actually

\footnotetext{
${ }^{18}$ Note that owing to the existence of multiple equilibria at the allocation level, there exist different games at the selling strategy level, depending on the choice of the allocation equilibrium. As in games where there exist multiple equilibria, we note that we may need to apply some equilibrium refinement notions to address the question of which equilibrium will actually realize. However, our context is really a co-ordination game where upon each firm choosing the conventional selling strategy, the allocation equilibrium is either $(3,1)$ or $(1,3)$. Thus, as in the spirit of coordination games with a repeated flavor, we propose that if the game is repeated over time, which it is in reality, then firms may need to alternate over their allocation strategies of 1 and 3 respectively. The fact that firms are in the same game over time should provide incentives for each firm to abide by the co-ordination for fear of being 'penalized' using some trigger strategy or the tit-for-tat strategy.
} 
not to oversell. This is because by not overselling, pricing competition in Period 2 is muted and as a result, the pricing competition (which does not exist if the early demand is large) in Period 1 is also muted as the opportunity to sell in Period 2 presents itself as a more attractive option (than Period 1) for the overselling firm. As shown in Lim (2009), overselling naturally intensifies the pricing competition in Period 2 so much so that it may lead to Pareto-dominated outcome, i.e., overselling is a weakly dominant strategy yet firms are worse off at the equilibrium by adopting the weakly dominant strategy when the demand in Period 1 is high. Here, we show that when the demand in Period 1 is not sufficiently high and thus is subjected to pricing competition between the firms, any negative impact from the pricing competition in Period 2 spills over to Period 1. Put differently, the negative impact on prices in both periods from overselling is magnified once Period 1 is not shielded from pricing competition. In the following, we consider an example that further illustrates this observation when the demands in both periods are correlated.

Example 2 (Correlated Demands). Consider two symmetric firms such that $v_{1}=1, v_{2}=$ $2, \tau \in\{1.2,1.4\}$ and $N=2$. Let $X_{1}, X_{2}$ be dependent with the following joint distribution: $P\left(X_{1}=0, X_{2}=0\right)=P\left(X_{1}=1, X_{2}=0\right)=P\left(X_{1}=3, X_{2}=2\right)=P\left(X_{1}=3, X_{2}=3\right)=P\left(X_{1}=\right.$ $\left.3, X_{2}=4\right)=P\left(X_{1}=5, X_{2}=0\right)=0.1, P\left(X_{1}=3, X_{2}=5\right)=P\left(X_{1}=4, X_{2}=1\right)=P\left(X_{1}=\right.$ $\left.4, X_{2}=2\right)=P\left(X_{1}=5, X_{2}=1\right)=0.05, P\left(X_{1}=2, X_{2}=0\right)=0.2$, and $P\left(X_{1}=x_{1}, X_{2}=x_{2}\right)=0$, otherwise.

First, a careful examination of the joint probability distribution reveals that there is a higher probability that the demand in Period 1 is larger than that in Period 2. Secondly, we note that in this example, the total capacity of the firms is $2 N=4$. Yet the maximum demand in each period $X_{t}$ is 5 . Thus, this example presents a scenario in which the potential demand in the market is significantly higher than the total capacity. This thus provides a context for the overselling strategy to be dominant. However, we shall see that this is not always the case. Tables 5, 6 and 7 show the allocation game that is faced by the firms in the subgames $(C S, C S),(O S, O S)$ and $(C S, O S)$, respectively when $\tau=1.2$.

Table 5 shows that when both firms adopt conventional selling, there exist three equilibria at the allocation level. The expected profit outcome of $(1.6,1.6)$ where $k_{A}=k_{B}=1$ is Pareto- 


\begin{tabular}{|c|c|c|c|}
\hline$k_{A} \backslash k_{B}$ & 0 & 1 & 2 \\
\hline 0 & $(0.8,0.8)$ & $(1.3,1.57)$ & $\underline{(1.8,1.7)}$ \\
1 & $(1.57,1.3)$ & $\underline{(1.6,1.6)}$ & $(1.74,1.4)$ \\
2 & $\underline{(1.7,1.8)}$ & $(1.4,1.74)$ & $(1.55,1.55)$ \\
\hline
\end{tabular}

Table 5: Allocation Game for (CS,CS) in Example $2(\tau \in[1,2])$

dominated by the other two equilibria in which one observes are instances where the firm 'splits' the market, with the firm selling in Period 2 obtaining a slightly higher expected profit. Since there is no overselling and thus no compensation for reselling, the expected profits are independent of $\tau$. Suppose $\tau=1.2$. When both firms oversell, we find that one firm (say Firm $i$ ) allocates its entire capacity to Period 1 while the other firm allocates one unit to Period 1 at the equilibrium owing to the nature of the joint probability distribution that the demand in Period 1 is likely to be higher than that in Period 2. Again, there are two equilibria at the allocation level and the firm that allocates 2 units to Period 1 obtains a higher expected profit not just from the potentially higher demand in Period 1 but also the opportunity to oversell later in Period 2. Finally, when only one firm oversells, the allocations at equilibrium is $(1,2)$. The overselling firm is in a better position to hedge the demand risk in Period 2 by allocating two units to Period 1, thereby increasing its expected profit to 1.92 as compared to 1.61 for the firm which does not oversell. It is straightforward to see that overselling is a dominant strategy for each firm. More specifically, given that Firm $i$ adopts conventional selling, Firm $j$ obtains a profit of 1.7 or 1.8 by adopting the conventional selling strategy but a higher expected profit of 1.92 by overselling. Similarly, if Firm $i$ oversells, the expected profit of Firm $j$ is either 1.61 from conventional selling or at least 1.66 from overselling. Table 8 shows a particular case of the game at the selling strategy level. Thus, we conclude that when $\tau=1.2$, overselling is a dominant strategy. However, this conclusion no longer holds as $\tau$, the compensation takes on a larger value.

Similar observations on the allocation level hold when $\tau=1.4$ as shown in Tables 9 and 10 . However, as a higher $\tau$ reduces the attractiveness of the overselling strategy, the overselling strategy is no longer a dominant strategy. In fact, there does not necessarily exist any dominant strategy as 


\begin{tabular}{|c|c|c|c|}
\hline$k_{A} \backslash k_{B}$ & 0 & 1 & 2 \\
\hline 0 & $(0.8,0.8)$ & $(1.1,1.52)$ & $(1.4,2.02)$ \\
1 & $(1.52,1.1)$ & $(1.42,1.42)$ & $\underline{(1.66,1.72)}$ \\
2 & $(2.02,1.4)$ & $\underline{(1.72,1.66)}$ & $(1.47,1.47)$ \\
\hline
\end{tabular}

Table 6: Allocation Game for (OS,OS) in Example $2(\tau=1.2)$

\begin{tabular}{|c|c|c|c|}
\hline$k_{A} \backslash k_{B}$ & 0 & 1 & 2 \\
\hline 0 & $(0.8,0.8)$ & $(1.1,1.52)$ & $(1.4,2.02)$ \\
1 & $(1.57,1.3)$ & $(1.57,1.8)$ & $\underline{(1.61,1.92)}$ \\
2 & $(1.7,1.8)$ & $(1.4,2.06)$ & $(1.55,2.27)$ \\
\hline
\end{tabular}

Table 7: Allocation Game for (CS,OS) in Example $2(\tau=1.2)$

\begin{tabular}{|c|c|c|}
\hline$\lambda_{A} \backslash \lambda_{B}$ & CS & OS \\
\hline CS & $(1.8,1.7)$ & $(1.61,1.92)$ \\
OS & $(1.92,1.61)$ & $(1.66,1.72)$ \\
\hline
\end{tabular}

Table 8: Selling Strategy Game in Example $2(\tau=1.2)$ 


\begin{tabular}{|c|c|c|c|}
\hline$k_{A} \backslash k_{B}$ & 0 & 1 & 2 \\
\hline 0 & $(0.8,0.8)$ & $(1.15,1.49)$ & $(1.5,1.94)$ \\
1 & $(1.49,1.15)$ & $(1.39,1.39)$ & $\underline{(1.681,1.64)}$ \\
2 & $(1.94,1.5)$ & $\underline{(1.64,1.681)}$ & $(1.44,1.44)$ \\
\hline
\end{tabular}

Table 9: Allocation Game for (OS,OS) in Example $2(\tau=1.4)$

\begin{tabular}{|c|c|c|c|}
\hline$k_{A} \backslash k_{B}$ & 0 & 1 & 2 \\
\hline 0 & $(0.8,0.8)$ & $(1.15,1.49)$ & $(1.5,1.94)$ \\
1 & $(1.567,1.3)$ & $(1.583,1.75)$ & $\underline{(1.641,1.79)}$ \\
2 & $(1.7,1.8)$ & $(1.4,1.981)$ & $(1.55,2.09)$ \\
\hline
\end{tabular}

Table 10: Allocation Game for (CS,OS) in Example $2(\tau=1.4)$

it depends on which allocation is chosen under the various subgames. Tables 11 and 12 show that there exists an equilibrium where only one firm oversells or the equilibrium can even involve the use of mixed strategies. It is straightforward to verify that $(O S, O S)$ is no longer an equilibrium here. More specifically, if Firm $i$ adopts overselling, Firm $j$ gets a payoff of 1.658 by adopting conventional selling. Thus, it is a best response for Firm $j$ to oversell if its payoff from doing so is 1.69 instead of 1.6, that is, the allocation in the subgame $(O S, O S)$ has to be $k_{i}=2, k_{j}=1$. Bearing this in mind, the best response for Firm $i$ as a result is no longer to oversell (whcih gives a payoff of 1.6) since conventional selling gives a payoff of at least 1.7.

In summary, these examples suggest that the allocation rule is more complex once the demand in

\begin{tabular}{|c|c|c|}
\hline$\lambda_{A} \backslash \lambda_{B}$ & CS & OS \\
\hline CS & $(1.8,1.7)$ & $\frac{(1.641,1.79)}{(1.64,1.681)}$ \\
OS & $(1.79,1.641)$ & $(1.64,1.6$ \\
\hline
\end{tabular}

Table 11: Selling Strategy Game in Example $2(\tau=1.4)$, Asymmetric Equilibrium 


\begin{tabular}{|c|c|c|}
\hline$\lambda_{A} \backslash \lambda_{B}$ & CS & OS \\
\hline CS & $(\underline{1.8}, 1.7)$ & $(1.641, \underline{1.79})$ \\
OS & $(1.79, \underline{1.641})$ & $(\underline{1.681}, 1.64)$ \\
\hline
\end{tabular}

Table 12: Selling Strategy Game in Example $2(\tau=1.4)$, Mixed Strategy Equilibrium

Period 1 is no longer large. Clearly, when this allocation rule is taken into consideration to analyze the selling strategies at the equilibrium, it renders the analysis even more complex. Following from the examples above, it is clear that the overselling strategy loses its shine once the demand in Period 1 is not sufficiently high to guarantee the sale of all available capacities. The main reason is the early demand uncertainty leads to a spillover effect of pricing competition in Period 2 to Period 1. This magnifies the negative impact of the overselling strategy so much so that it renders it undesirable as part of an equilibrium. 


\section{Discussion and Conclusion}

Traditionally in the operations management literature, studies have focused on pricing and capacity allocation strategies when there is demand uncertainty. In this paper, we extend studies in this area to consider the impact of incorporating the overselling strategy when demand uncertainty occurs over multiple periods. The overselling strategy is not uncommon, particularly in the service industries where purchase and consumption times do not coincide. That is, goods (or services) may be purchased earlier and consumption takes place only at a later time.

Our contributions are three-fold. First, we enrich the extant literature by focusing on the value of overselling as market structure shifts between monopoly and duopoly. In absence of competition, we strengthen the main result of Biyalogorsky et al (1999) by showing that overselling continues to shine as the optimal selling strategy even when early arrival can be limited. Second, we show that overselling by both firms as a (weakly) dominant strategy may fail to hold in a competitive setting. The roadmap of our analysis is based on formalizing the equilibrium pricing strategies in both periods. This leads to our critical finding where we show that stochastic early demand (that are not sufficiently high to guarantee the sale of all units allocated to the early period) can result in genuine pricing competition, causing overselling loses its shine as a weakly dominant strategy in a duopoly regime. Third, whether the equilibrium sees any firm adopting the overselling strategy depends not just on the market characteristics, as identified by the demand arrivals in the early and late periods, the consumers' valuations and firm characteristics such as the capacity, the capacity allocation at the equilibrium are also important factors in determining the selling strategies at the equilibrium. These observations are made through various numerical examples. In particular, we show that when the early period is not immune to pricing competition, it will bear the impact of pricing competition in the late period, thus excavating any negative effect owing to the overselling strategy (Example 1). In addition, different choices of the capacity allocations at the equilibrium can indeed lead to different selling strategies at the equilibrium all else being the same (see Example 2 in §3.3). Thus, our research offers a word of caution to guard against complacency in assuming that overselling is always a weakly dominant strategy when a firm is operating as part of a duopoly. To answer the questions raised in the opening paragraph, an equilibrium can indeed exist where 
one firm finds it profitable to refrain from overselling even when the competing firm oversells once early demand is uncertain.

\begin{tabular}{|c|c|c|}
\hline $\begin{array}{ll}\text { early arrival } \\
\text { assumption }\end{array}$ & monopoly & duopoly \\
\hline deterministic & $\begin{array}{l}\text { overselling is optimal whenever arrival } \\
\text { exceeds capacity } \\
\text { (Biyalogorsky et al 1999) }\end{array}$ & $\begin{array}{l}\text { overselling is (weakly) } \\
\text { dominant whenever arrival } \\
\text { exceeds capacity; } \\
\text { no pricing competition } \\
\text { (Lim 2010) }\end{array}$ \\
\hline stochastic & $\begin{array}{l}\text { overselling is optimal whenever arrival is } \\
\text { random }\end{array}$ & $\begin{array}{l}\text { overselling is not necessarily } \\
\text { (weakly) dominant } \\
\text { whenever arrival is random; } \\
\text { mixed strategy pricing } \\
\text { competition }\end{array}$ \\
\hline
\end{tabular}

Figure 1: Market Structure and Impact on the Value of Overselling

Our research thus suggests that managers should examine not just the market structure and firm characteristics when considering their pricing and selling strategies. More importantly, they need to convey the value proposition to competing firms regarding the need, or rather, the merits of co-ordinating at the capacity allocation level to lead to a more favorable win-win profit outcome. As our analyses have shown, there often exist multiple equilibria both at the capacity allocation level as well as the selling strategy level. More co-ordination can certainly facilitate the occurrence of an equilibrium outcome. As can be seen, more airlines are already forming alliances and code-sharing their flights. Such practice clearly helps to coordinate the number of units available for sale in each time period. Our research suggests that perhaps more coordination and information sharing can further benefit the firms in terms of achieving mutually favorable selling strategy equilibria. In addition, other industries (such as the hotel industry) perhaps can also take a leaf from the co-operative behavior between airlines to further enhance their profitability. Much as hotels offer less identical products and services than airlines, perhaps specific alliances may still be possible within hotels of similar offerings and close vicinities.

Clearly, there are limitations to our work. We have assumed in our model, that the arrival of consumers is exogenous. In the face of more strategic consumers who make their purchase decisions based not only on the current price, but also on the future anticipated price, future research may 
want to look into the possibility where consumers can choose their arrival time. Along the same vein, consumers in each period in our model, are homogeneous. Future work may seek to examine if the overselling strategy can maintain its shine should consumers in each period be heterogeneous.

\section{References}

Bitran, G., R. Caldentey. 2003. An overview of pricing models for revenue management. Manufacturing 83 Service Operations Management, 5(3), 203-229.

Biyalogorsky, E., Z. Carmon, G. E. Fruchter, E. Gerstner. 1999. Overselling with opportunistic cancellations. Marketing Science, 18(4), 605-610.

Chan, L. M. A., Z. J. Shen, D. Simchi-Levi, J.L. Swann. 2004. Coordination of pricing and inventory decisions: A survey and classification. Handbook of Quantitative Supply Chain Analysis: Modeling in the E-Business Era, D. Simchi-Levi, S.D. Wu amd Z. J. Shen eds. kluwers, 335-392. D.D. Sierag, G.M. Kooleb, R.D. van der Meia, J.I. van der Rest, B. Zwarta. 2015. Revenue management under customer choice behaviour with cancellations and overbooking European Journal of Operational Research, 246, 170-185.

Dai, Y., X. Chao, S. Fang, H. Nuttle. 2006. Capacity allocation with traditional and Internet channels. Navel Research Logistics, 53, 772-787.

Dana, J. D. 1999. Using yield management to shift demand when the peak time is unknown. RAND Journal of Economics, 30(3), 456-474.

Desiraju, R., S. Shugan. 1999. Strategic service planning and yield management. Journal of Marketing, 63(1), 44-56.

Elmaghraby, W., P. Keskinocak. 2003. Dynamic pricing in the presence of inventory considerations: Research overview, current practices, and future directions. Management Science, 49(10), 12871309.

Federgruen, A., A. Heching. 1999. Combined pricing and inventory control under uncertainty. Operations Research, 47(3), 454-475.

Gallego, G., G. van Ryzin. 1994. Optimal dynamic pricing of inventories with stochastic demand over finite horizons. Management Science, 40(8), 999-1020. 
Kalai, E., M. Kamien, M. Rubinovitch. 1992. Optimal service speeds in a competitive environment. Management Science, 38, 1154-1163.

Kirman, A., M. Sobel. 1974. Dynamic oligopoly with inventories. Econometrica, 42, 279-287.

Lan Y., Micheal, O.B., Itir Z.K., Jean Z.J.X., Gloria L.X. 2015. Analysis of seat allocation and overbooking decisions with hybrid information. European Journal of Operational Research, 240, 493-504.

Lim, W.S. 2009. Overselling in a competitive environment: Boon or bane? Marketing Science, 28(6), 1129-1143.

Lim, W.S. and Tang C. 2010. Optimal dynamic pricing strategies in the presence of speculators and forward looking consumers: Are speculators friends or foes? Production and Operations Management, 22(3), 571-587.

Lippman, S., K. McCardle. 1997. The competitive newsboy. Operations Research, 45(1), 54-65.

Littlewood, K. 1972. Forecasting and control of passengers bookings. AGIFORS 12th Annual Symposium Proceedings, 95-117.

Narasimhan, C. 1988. Competitive promotional strategies. Journal of Business, 61(4), 427-449.

Netessine S., R. Shumsky. 2002. Introduction to the theory and practice of yield management. INFORMS Transactions on Education, 3(1), 34-44.

Netessine S., R. Shumsky. 2005. Revenue management games: Horizontal and vertical competition. Management Science, 51(5), 813-831.

Parlar, M. 1988. Game theoretic analysis of the substitutable product inventory problem with random demand. Navel Research Logistics, 35, 397-409.

Philips, R. L. 2005. Pricing and Revenue Optimization. Stanford University Press, Stanford, CA.

Rothstein, M. 1971. An airline overbooking model. Transportation Science, 5(2), 180-92.

Rothstein, M. 1985. O.R. and the airline over-booking problem. Operations Research, 33, 237-248. Shugan, S., J. Xie. 2005. Advance selling as a competitive marketing tool. International Journal of Research in Marketing, 22(3), 351-373.

Staiger, R., F. Wolak. 1992. Collusive pricing with capacity constraints in the presence of demand uncertainty. Rand Journal of Economics, 23(2), 203-220. 
Su, X. 2010. Optimal Pricing with Speculators and Strategic Consumers. Management Science, $56(1), 24-40$.

Talluri, K. G. van Ryzin. 2004. The Art and Science of Revenue Management. Kluwer, New York. The China Post. 2009. Singapore Airlines to cut 17 percent of fleet. February 17.

USA Today. 1998. Giving up jet seat can be ticket to free ride. April 28, 05B.

Van Mieghem, J., M. Dada. 1999. Price versus production postponement: Capacity and competition. Management Science, 45(12), 1631-1649.

Weatherford, L., S. Bodily. 1992. A taxonomy and research overview of perishable-asset revenue management: Yield management, overbooking and pricing. Operations Research, 40(5), 831-844.

Wilson, C. 1988. On the optimal pricing policy of a monopolist. Journal of Political Economy, 96(1), 164-176.

Zhao, A., D. Atkins. 2008. Newsvendors under simultaneous price and inventory competition. Manufacturing \& Service Operations Management, 10(3), 539-546.

\section{Appendix $A$}

Table 13: Table of Notations

\begin{tabular}{ll}
\hline$A, B$ & firms in a duopoly \\
$N$ & capacity of Firm $i, i=A, B$ \\
$v_{t}$ & valuation of good for consumers who arrive in Period $t,(t=1,2)$ \\
$X_{t}$ & random variable to denote the no. of consumers arriving in Period $t,(t=1,2)$ \\
$\lambda_{i}\left(\lambda_{i}=C S, O S\right)$ & selling strategy of Firm $i$ \\
$k_{i}\left(\lambda_{i}, \lambda_{j}\right)$ & no. of units reserved for sale in Period 2 by Firm $i$ \\
& when the selling strategies are $\lambda_{i}, \lambda_{j}$ \\
$p_{i, t}\left(\lambda_{i}, \lambda_{j}\right)$ & price set by Firm $i$ for Period $t$ when the selling strategies are $\lambda_{i}, \lambda_{j}$ \\
$\tau$ & compensation to early consumer if good is resold in Period 2 \\
$\Pi_{i}^{\lambda_{i}, \lambda_{j}}$ & expected profit for Firm $i$ if selling strategies are $\lambda_{i}, \lambda_{j}$ \\
$D_{i, t}$ & demand of Firm $i$ in Period $t$ \\
$C_{i}$ & random variable to denote the beginning capacity of Firm $i$ in Period 2 \\
\hline
\end{tabular}




\subsection{Pricing Strategies at Equilibrium}

\section{Proof of Theorem 2.}

Proof. Without loss of generality, suppose Firm $A$ adopts a pure pricing strategy such that $p_{B, 2}<p_{A, 2} \leq v_{2}$. Then, $p_{A, 2}^{*}=v_{2}$ as the market share remains unchanged but the profit margin is higher. Given $p_{A, 2}^{*}=v_{2}$, Firm $B$ 's best response is to undercut since the profit margin is greater, i.e. $p_{B, 2}^{*}=v_{2}-\epsilon$. In response to $p_{B, 2}^{*}=v_{2}-\epsilon$, it is better off for Firm $A$ to undercut so that $p_{A, 2}^{*}=v_{2}-2 \epsilon$. Because $\hat{\phi}_{i}>\phi_{i}$ and $\hat{\rho}_{i}>\rho_{i}$ for $i \in\{A, B\}$, it is always beneficial (to gain market share) for the firm to undercut each other until $p_{A, 2}^{*}=0$, in which case Firm $B$ responds to this by setting $p_{B, 2}^{*}=v_{2}$, leading to another round of price undercutting. Hence, any pricing strategy at the equilibrium must necessarily be a mixed strategy.

Next, we characterize the mixed strategy at the Nash equilibrium. Suppose $U_{i}^{*}$ is the equilibrium pricing strategy set for firm $i$, for $i \in\{A, B\}$. Similar to Narasimhan (1988), it can be shown that the strategy sets can only be one of four continuous intervals, i.e. $U_{i}^{*} \in\left\{\left(l, v_{2}\right),\left[l, v_{2}\right),\left(l, v_{2}\right],\left[l, v_{2}\right]\right\}$. Suppose $U_{A}^{*}=\left[l_{A, 2}, v_{2}\right]$. At the subgame perfect Nash equilibrium, firm A must be indifferent among all prices in $U_{A}^{*}$. Hence, we equate $\Pi_{A, 2}\left(l_{A, 2}, p_{B, 2}\right)=l_{A, 2} \hat{\phi}_{A}+\left(l_{A, 2}-\tau\right) \hat{\rho}_{A}$ and $\Pi_{A, 2}\left(v_{2}, p_{B, 2}\right)=$ $v_{2} \phi_{A}+\left(v_{2}-\tau\right) \rho_{A}$ to obtain

$$
l_{A, 2}=\frac{v_{2}\left(\phi_{A}+\rho_{A}\right)+\tau\left(\hat{\rho}_{A}-\rho_{A}\right)}{\hat{\phi}_{A}+\hat{\rho}_{A}} .
$$

We can obtain $l_{B, 2}$ in a similar manner. However, $l$ can only be either $l_{A, 2}$ or $l_{B, 2}$. By definition, $l_{i_{2}^{*}, 2}>l_{-i_{2}^{*}, 2}$. Hence, firm $-i_{2}^{*}$ has incentive to price at $l_{i_{2}^{*}, 2}$ instead of pricing at $\left[l_{-i_{2}^{*}, 2}, l_{i_{2}^{*}, 2}\right)$. This allows firm $-i_{2}^{*}$ to earn a profit greater than what it would at price $v_{2}$. Hence, in equilibrium firm $-i_{2}^{*}$ cannot have a mass point at $v_{2}$, i.e. $U_{-i_{2}^{*}}^{*}=\left[l_{2}, v_{2}\right)$. As in Narasimhan (1988), we also get

$U_{i_{2}^{*}}^{*}=\left[l_{2}, v_{2}\right]$. Next, we derive the probability distribution functions $\sigma_{i_{2}^{*}}$ and $\sigma_{-i_{2}^{*}}$. Suppose firm $i_{2}^{*}$ sets price $y \in\left[l_{2}, v_{2}\right)$. Then, the profit should be equal to the profit obtained at $v_{2}$.

$$
v_{2} \phi_{i_{2}^{*}}+\left(v_{2}-\tau\right) \rho_{i_{2}^{*}}=\left[y \hat{\phi}_{i_{2}^{*}}+(y-\tau) \hat{\rho}_{i_{2}^{*}}\right]\left[1-\sigma_{-i_{2}^{*}}(y)\right]+\left[y \phi_{i_{2}^{*}}+(y-\tau) \rho_{i_{2}^{*}}\right] \sigma_{-i_{2}^{*}}(y) .
$$


Similarly, suppose firm $-i_{2}^{*}$ sets price $y \in\left[l_{2}, v_{2}\right)$. Then, the profit should be equal to the profit obtained at $l_{2}$.

$$
l_{2} \phi_{-i_{2}^{*}}+\left(l_{2}-\tau\right) \rho_{-i_{2}^{*}}=\left[y \hat{\phi}_{-i_{2}^{*}}+(y-\tau) \hat{\rho}_{-i_{2}^{*}}\right]\left[1-\sigma_{i_{2}^{*}}(y)\right]+\left[y \phi_{-i_{2}^{*}}+(y-\tau) \rho_{-i_{2}^{*}}\right] \sigma_{i_{2}^{*}}(y) .
$$

It follows that for $y \in\left[l_{2}, v_{2}\right)$,

$$
\begin{gathered}
\sigma_{-i_{2}^{*}}(y)=\frac{y \hat{\phi}_{i_{2}^{*}}+(y-\tau) \hat{\rho}_{i_{2}^{*}}-v_{2} \phi_{i_{2}^{*}}-\left(v_{2}-\tau\right) \rho_{i_{2}^{*}}}{y\left(\hat{\phi}_{i_{2}^{*}}-\phi_{i_{2}^{*}}\right)+(y-\tau)\left(\hat{\rho}_{i_{2}^{*}}-\rho_{i_{2}^{*}}\right)} \\
\sigma_{i_{2}^{*}}(y)=\frac{\left(y-l_{2}\right)\left(\hat{\phi}_{-i_{2}^{*}}+\hat{\rho}_{-i_{2}^{*}}\right)}{y\left(\hat{\phi}_{-i_{2}^{*}}-\phi_{-i_{2}^{*}}\right)+(y-\tau)\left(\hat{\rho}_{-i_{2}^{*}}-\rho_{-i_{2}^{*}}\right)}
\end{gathered}
$$

It can be verified that $\sigma_{i_{2}^{*}}\left(l_{2}\right)=\sigma_{-i_{2}^{*}}\left(l_{2}\right)=0, \sigma_{-i_{2}^{*}}\left(v_{2}\right)=1$, and

$$
\sigma_{i_{2}^{*}}\left(v_{2}\right)=\frac{\left(v_{2}-l_{2}\right)\left(\hat{\phi}_{-i_{2}^{*}}+\hat{\rho}_{-i_{2}^{*}}\right)}{v_{2}\left(\hat{\phi}_{-i_{2}^{*}}-\phi_{-i_{2}^{*}}\right)+\left(v_{2}-\tau\right)\left(\hat{\rho}_{-i_{2}^{*}}-\rho_{-i_{2}^{*}}\right)}<1 .
$$

Hence, $\sigma_{-i_{2}^{*}}$ has no mass point at $v_{2}$ while $\sigma_{i_{2}^{*}}$ has a mass point at $v_{2}$ equal to $1-\sigma_{i_{2}^{*}}\left(v_{2}\right)$. Finally, the equilibrium payoffs follow by definition.

Proof of Theorem 3. Proof. The proof is similar to the proof of Theorem 2.

\subsection{Capacity Allocation Rule at Equilibrium}

We first define $\kappa, \bar{\kappa}, \kappa^{R}$ as follows before we analyze each subgame respectively.

$$
\begin{aligned}
\kappa & =\inf \left\{y \in \mathbf{N}: P\left(X_{2} \geq 2 N-y\right)>\frac{v_{1}}{v_{2}}\right\}, \\
\bar{\kappa} & =\inf \left\{x \in \mathbf{N}: P\left(X_{1}>x\right)=0\right\}, \\
\kappa^{R} & =\inf \left\{y \in \mathbf{N}: P\left(X_{2} \geq 2 N-y\right)>\frac{v_{1}}{\tau}\right\}
\end{aligned}
$$

Note that $\kappa^{R} \geq \kappa$.

Lemma 2 (Symmetric equilibrium). $\left(\left(\lambda_{A}, \lambda_{B}\right)=(C S, C S)\right)$. Suppose both firms adopt the conventional selling strategy. Then Firm $i$ allocates $k_{i}^{C S, C S}(=k)$ units for sale in Period 1 , where $k$ is such that

$$
v_{1}>v_{2} P\left(X_{2} \geq 2 N-2 k+1 \mid X_{1} \geq 2 k\right)
$$


$j \neq i, j=A, B$. More specifically, when the arrivals $X_{1}$ and $X_{2}$ are independent, $k=\min (\min (\kappa, \bar{\kappa})-$ $k, N)$.

Proof. Consider the subgame where both firms adopt the conventional selling strategy. Let $k_{i}^{C S, C S}=k_{j}^{C S, C S}=k$ denote the symmetric allocations for Firm $i$ and Firm $j$ at the equilibrium. Given $k_{j}^{C S, C S}, k_{i}^{C S, C S}$ must satisfy $\Pi_{i}^{C S, C S}\left(k_{i}^{C S, C S}, k_{j}^{C S, C S}\right)-\Pi_{i}^{C S, C S}\left(k_{i}^{C S, C S}-1, k_{j}^{C S, C S}\right)>0$, which simplifies to $v_{1} P\left(X_{1} \geq k_{i}^{C S, C S}+k_{j}^{C S, C S}\right)-v_{2} P\left(X_{1} \geq k_{i}^{C S, C S}+k_{j}^{C S, C S}, X_{2} \geq 2 N-\left(k_{i}^{C S, C S}+\right.\right.$ $\left.\left.k_{j}^{C S, C S}\right)+1\right)$. If particular, if $X_{1}, X_{2}$ are independent, $k_{i}^{C S, C S}=\inf \left\{x \leq N: P\left(X_{2} \geq 2 N-(x+\right.\right.$ $\left.\left.\left.k_{j}^{C S, C S}\right)\right)>\frac{v_{1}}{v_{2}}\right\} \wedge\left[\bar{\kappa}-k_{j}^{C S, C S}\right]^{+}=\min \left(\min (\kappa, \bar{\kappa}), k_{j}^{C S, C S}, N\right)$. The second inequality holds when $P\left(X_{1} \geq k_{j}^{C S, C S}+k_{i}\right)>0$ and $X_{1}, X_{2}$ are independent.

Lemma 3 (Symmetric equilibrium). $\left(\left(\lambda_{A}, \lambda_{B}\right)=(O S, O S)\right)$. Suppose both firms adopt the overselling strategy. Then Firm $i$ allocates $k_{i}^{O S, O S}(=k)$ units for sale in Period 1 , where $k$ is such that

$$
v_{1}>(1+\alpha) v_{1} P\left(X_{2} \geq 2 N-k+1 \mid X_{1} \geq 2 k\right)
$$

$j \neq i, j=A, B$. More specifically, when the arrivals $X_{1}$ and $X_{2}$ are independent, $k=\min \left(\kappa^{R},[\bar{\kappa}-\right.$ $\left.k]^{+}, N\right)$.

Proof. Consider the subgame where both firms adopt the overselling strategy. Let $k_{i}^{O S, O S}=$ $k_{j}^{O S, O S}=k$ denote the symmetric allocations for Firm $i$ and Firm $j$ at the equilibrium. Given $k_{j}^{O S, O S}, k_{i}^{O S, O S}$ must satisfy $\Pi_{i}^{O S, O S}\left(k_{i}^{O S, O S}, k_{j}^{O S, O S}\right)-\Pi_{i}^{O S, O S}\left(k_{i}^{O S, O S}-1, k_{j}^{O S, O S}\right)>0$, which simplifies to $v_{1} P\left(X_{1} \geq k_{i}^{O S, O S}+k_{j}^{O S, O S}\right)-(1+\alpha) v_{1} P\left(X_{1} \geq k_{i}^{O S, O S}+k_{j}^{O S, O S}, X_{2} \geq 2 N-k_{i}^{O S, O S}+1\right)$. If particular, if $X_{1}, X_{2}$ are independent, $k_{i}^{O S, O S}=\inf \left\{x \leq N: P\left(X_{2} \geq 2 N-X\right)>\frac{1}{1+\alpha}\right\} \wedge[\bar{\kappa}-$ $\left.k_{j}^{O S, O S}\right]^{+}=\min \left(\kappa^{R},\left[\bar{\kappa}-k_{j}^{O S, O S}\right]^{+}, N\right)$. The second inequaltiiy holds when $P\left(X_{1} \geq k_{j}^{O S, O S}+k_{i}\right)>0$ and $X_{1}, X_{2}$ are independent. 